\title{
Learning from a crisis
}

\author{
José G Merino US clinical research editor, BMJ
}

Washington, DC

Famines induced by war and economic and social crises are humanitarian tragedies. But they are also "tragic experiments" that shed light on the health effects of food deprivation. Studies of adults born of mothers who were pregnant during the Dutch Hunger Winter at the end of the second world war and of the Chinese famine of 1959-61, for example, contributed to our understanding of the effect of in utero deprivation on adult physical and mental health.

In this week's issue, Manuel Franco from the Johns Hopkins Bloomberg School of Public Health and colleagues from Cienfuegos in Cuba and Alcalá de Henares in Spain report an unfortunate "30-year natural experiment" precipitated by the economic crisis in Cuba in the early 1990s and the recovery that followed (doi:10.1136/bmj.f1515). Food scarcity during the crisis led to population-wide weight loss and, as a consequence, rapid declines in diabetes and heart disease. Franco and colleagues found that by 1995, when the economy improved, the prevalence of obesity started to increase, and exceeded pre-crisis levels by 2011. The upward weight trend was accompanied by a large increase in diabetes incidence and prevalence, and six years into the weight rebound phase, diabetes mortality increased. Interestingly, changes in weight, diet, and physical activity had an impact on diabetes, hypertension, and cardiac disease in a short time, months and years rather than decades.

In an accompanying editorial (doi:10.1136/bmj.f1777), Walter Willett highlights the fact that a greater access to bicycles during the crisis may have contributed to the weight loss and beneficial health effects, and that decreased rates of physical activity accompanied the economic recovery.

"Although the hardships experienced by Cubans in the 1990s were unfortunate, the present findings add powerful evidence that major population-wide benefits will be obtained rapidly by reducing overweight and obesity. To achieve this is perhaps the major public health and societal challenge of this century," writes Willett.

Studies such as the one done by Franco and colleagues support the implementation of population-wide interventions to curb obesity, diabetes, cancer, and cardiovascular disease. Several US cities have implemented initiatives to promote exercise and healthier diets by banning the use of trans fats and posting calorie counts on menus. Mayor Bloomberg of New York City banned the sale of supersized sodas-an initiative that was blocked by a state Supreme Court judge. Bike sharing programs that foster the use of bicycles rather than cars for short trips and an extensive network of bike lanes are now common in many cities.

But more studies are needed to prove that population-wide interventions are effective because the data are not conclusive. On 19 October 2012, for example, the National Institutes of Health reported that the Look AHEAD (Action for Health in Diabetes) study, which investigated how a lifestyle intervention for weight control affected rates of heart disease, stroke, and cardiovascular related deaths in overweight and obese people with type 2 diabetes, was stopped early after finding no harm, but no cardiovascular benefits.

The research by Franco and colleagues is posted with one of our first video abstracts. We invite you to watch it and send us your comments (doi:10.1136/bmj.f1515).

\section{Cite this as: BMJ 2013:346:f2321}

๑ BMJ Publishing Group Ltd 2013 